\title{
(c) (1) \\ Overall survival prediction in metastatic castration-resistant prostate cancer treated with radium-223
}

\author{
Monica Vidal ${ }^{1}$, Alejandro Delgado ${ }^{1}$, Carlos Martinez ${ }^{2}$, José Jaime Correa ${ }^{2}$, Isabel Cristina Durango ${ }^{3}$ \\ ${ }^{1}$ Department of Radiology, Hospital Pablo Tobon Uribe, Medellin, Antioquia, Colombia; ${ }^{2}$ Department of \\ Urology, Hospital Pablo Tobon Uribe, Medellin, Antioquia, Colombia; ${ }^{3}$ Department of Oncology, Hospital \\ Pablo Tobon Uribe, Medellin, Antioquia, Colombia
}

\section{ABSTRACT}

Objective: Radium-223(223Ra) is indicated for patients (p) with metastatic castration resistant prostate cancer ( $\mathrm{mCRCP}$ ). Objectives: The aim of this study was to evaluate the role of baseline clinical variables associated with overall survival (OS) and toxicity of 223Ra. Its purpose was to identify the factors that can predict a better response to treatment and provide information regarding the most appropriate time for the application of 223Ra.

Materials and Methods: Prospective study in 40p with mCRPC treated with 223Ra. End points were OS, progression-free survival and time to progression. The follow-up parameters were: doses received, hemoglobin $(\mathrm{Hb})$, absolute neutrophil count (ANC), platelet count (PC), prostate specific antigen (PSA), alkaline phosphatase (ALP), Visual Analogue Scale for pain, Eastern Cooperative Oncology Group (ECOG) and WHO's Cancer Pain Ladder. The use of other treatments was also evaluated.

Results: Median OS was 17.1 months(mo) (CI95\%6.5-27.7); 26/40p received complete treatment of 223Ra, without reaching a median $0 S$ and $14 \mathrm{p}$ received incomplete treatment with a median OS 13.6mo(CI95\%1.6-25.6). Median follow-up was $11.2 \mathrm{mo}$ (range:1.3-45.2). The univariate analysis showed that factors as VAS, ECOG, Hb and ALP values were independently associated with OS. First line treatment with 223Ra was started in 11/40p, while $19 p$ had been heavily pre-treated and $13 p$ received concomitant treatment.

Conclusions: 223Ra therapy require an adequate selection of patients to obtain the greatest clinical benefit. Low basal $\mathrm{Hb}$, hight basal ALP, bone marrow involvement and an altered ECOG were the main factors that decreased OS in our patients. 223Ra should be considered relatively early in the course of treatment.

\section{ARTICLE INFO}

\section{Monica Vidal}

http://orcid.org/0000-0003-2003-7954

Keywords:

Radium-223 [Supplementary

Concept]; Castration; Prostatic

Neoplasms

Int Braz J Urol. 2020; 46: 599-611

Submitted for publication:

August 01, 2019

Accepted after revision:

October 22, 2019

Published as Ahead of Print:

March 12, 2020

\section{INTRODUCTION}

The frequency of new cases of prostate cancer reported by The Global Cancer Observatory was 12.712 in Colombia for 2018 (1). Additionally, the incidence of metastatic castration-resistant prostate cancer (mCRPC) is increasing, of which the most common are bone metastases. Mortality secondary to mCRPC is related to the metastatic event, therefore, the increasing incidence of bone metastases represents an ideal target for improving outcomes. Bone metastases are a common cause of morbidity and mortality and pose a secondary economic burden on healthcare. Skeletal 
related events (SREs) continue to be a major cause of disability, diminished quality of life (QoL), and increased cost for treatment of complications (2).

Until 2004, chemotherapy was the main treatment for mCRPC. Since then, different strategies have emerged with novel agents to manipulate the androgen-receptor, targeting the immune system and treating the bone micro-environment.

Traditionally, bone pain has been managed with analgesics, external beam radiation-therapy (EBRT), and beta-emitting radioisotopes. While some of the current standard treatments, such as bisphosphonates, rank ligand inhibitors, and bone-seeking beta-emitters like strontium, have been shown to length the progression time, none have demonstrated a survival advantage (3). The development of others agents, including cabazitaxel, cellular immunotherapy-(sipuleucel-T), androgen biosynthesis inhibitors-(abiraterone), androgen receptor antagonists-(enzalutamide), and targeted therapy for bone metastases with Radium-223 dichloride (223Ra) (4) have been of great benefit, but there is uncertainty regarding the optimal use of these treatments in sequence and in combination.

223Ra is the sixth novel agent to be added to the treatment of mCRPC, having been approved by the Food and Drug Administration on May, 2013, and this treatment was later incorporated into the National Comprehensive Cancer Network guidelines $(5,6)$. This approval was based on the results of the randomized, double-blinded, multinational clinical trial titled ALSYMPCA-(ALpharadin in SYMptomatic Prostate CAncer) (7).

ALSYMPCA compared 223Ra with placebo in men with mCRPC with symptomatic bone metastases and no visceral metastases. In this clinical trial incorporating 307 patients (p) in the placebo arm and $614 \mathrm{p}$ in the treatment arm. The clinical trial demonstrated a 3.6 month (mo) overall survival (OS) benefit with 223Ra, in comparison to the placebo (median14.9 vs.11.3mo HR 0.70, 95\% CI: $0.58-0.83, \mathrm{p}<0.001)(7)$.

223Ra is an alpha emitter and calcium-mimetic that targets the hydroxyapatite matrix in the bone, thereby accumulating in areas of active bone remodeling and formation, such as sites of osteoblastic bone metastases (8-10). Despite the increasing clinical use of 223Ra in mCRPC, clinical variables that may predict responses are still difficult to identify $(11,12)$. The aim of this single-center prospective study was to evaluate the role of baseline clinical variables associated with the OS and toxicity of 223Ra therapy. Its purpose was to identify the factors that can predict a better response to treatment and provide information regarding the most appropriate time for the application of 223Ra.

\section{MATERIALS AND METHODS}

\section{Study design}

This prospective study was conducted between November 2014 and April 2018 with 40p with mCRPC treated with 223Ra in the nuclear medicine department at Pablo Tobón Uribe Hospital. The study was approved by the local ethical committee and conducted in accordance with Helsinki Declaration.

\section{Patients}

Patients were included if they had bone pain, two or more bone metastases on bone-scintigraphy, and absence of visceral metastasis in thoracic and abdomino-pelvic-CT. Before the first administration of 223Ra, the absolute neutrophil count (ANC) was $\geq 1.5 \times 109 / \mathrm{L}$, hemoglobin $(\mathrm{Hb})$ was $\geq 10 \mathrm{~g} / \mathrm{dL}$, and the platelet count $(\mathrm{PC})$ was $\geq 100 \times 109 /$ L. During subsequent administrations, the ANC was $\geq 1 \times 109 / \mathrm{L}$, and PC was $\geq 50 \times 109 / \mathrm{L}$.

\section{Ra treatment}

223Ra is a emitting alpha-particle with a short range of $2-10$ cell bodies $(10 \mu \mathrm{m})$ and a physical half-life of 11.43 days. It has a complicated decay scheme with a series of six daughter products before decaying to stable lead. The total emitted energy is $28.2 \mathrm{MeV}$, of which $93.5 \%$ are $\alpha$-emissions (average energy of $5.78 \mathrm{MeV}$ ), less than $3.6 \%$ is $\beta$-particle, and less than $1.1 \%$ are $\gamma$-emissions (154keV). This results in a low signal which can present challenges for quantitative imaging, but nevertheless, introduces the potential for individualized biodistribution studies. The treatment consisted of 6 cycles every 4 weeks. The standard dose is $55 \mathrm{kBq} / \mathrm{kg}$. 


\section{Evaluation and follow-up}

Before and after treatment, the patients were clinically evaluated using Eastern Cooperative Oncology Group (ECOG), WHO's Cancer Pain Ladder (CPL) and Visual Analogue Scale for pain (VAS) to evaluate the level of functioning, the decrease in consumption of opioid analgesics, and the reduction of skeletal pain, respectively (Table-1). Bone-scintigraphy was achieved before and after 223Ra-treatment. Skeletal tumor burden was classified as low when the number of bone metastases was between 2-6, intermediate $>6$, and high burden in the presence of diffuse disease (superscan). Laboratory tests were assessed before, during, and after 223Ra treatment with ANC, $\mathrm{Hb}, \mathrm{PC}$, prostate specific antigen (PSA), lactate dehydrogenase (LDH), and alkaline phosphatase (ALP). The use of chemotherapy, abiraterone, enzalutamide, bisphosphonates, and EBRT was also evaluated.

Response criteria

Response to treatment was defined as a sustained reduction in skeletal symptoms (VAS), an increase in the level of functioning (ECOG), a decrease in consumption of opioid analgesics (CPL), and a reduction in ALP levels between the first cycle and 1-3mo after the last cycle of 223Ra.

The response rate was defined in terms of ALP change, such as if there was a reduction $>25 \%$, if there was a reduction $<25 \%$, if there was an increase in ALP $<25 \%$, and if there was an increase in ALP levels $>25 \%$.

The main endpoint was OS, which was established as from initial 223Ra cycle until either the date of death from any cause or the last follow-up. Patients who were alive at the last follow-up date were censored. Other factors were evaluated, such as progression-free survival (PFS), which was established from initial 223Ra cycle until date of objective tumor progression, death by any cause, or last follow-up, and time to progression (TTP), which was assessed from the date of initial 223Ra cycle to date of objective tumor progression (defined as a lesion progressing in the bone, nodal or visceral lesions). Patients who were alive and did not experience an event (progression or SREs) were censored.

\section{Table 1 - Classification of ECOG, CPL and VAS.}

\begin{tabular}{|c|c|c|c|}
\hline \multicolumn{2}{|c|}{ Visual analogue scale for pain (VAS) } & \multicolumn{2}{|r|}{ WHO’s Cancer Pain Ladder (CPL) } \\
\hline 0 & No & 0 & No pain. Analgesia not required \\
\hline 1 & Mild & 1 & Mild pain. No opioid use \\
\hline 2 & & 2 & Moderate pain. Occasional opioid use \\
\hline 3 & & 3 & Severe pain. Daily opioid use \\
\hline 4 & Moderate & \multicolumn{2}{|r|}{ ECOG STATUS } \\
\hline 5 & & 0 & $\begin{array}{l}\text { Asymptomatic. Fully active, able to carry on all activities without } \\
\text { restriction }\end{array}$ \\
\hline 6 & & 1 & $\begin{array}{l}\text { Symptomatic. Restricted in physically strenuous activity. Able to } \\
\text { carry out work of a light or sedentary nature }\end{array}$ \\
\hline 7 & Severe & 2 & $\begin{array}{l}\text { Symptomatic. }<50 \% \text { in bed during the day. Ambulatory and } \\
\text { cupable of all self-care. Unable to carry out any work activities }\end{array}$ \\
\hline 8 & & 3 & $\begin{array}{l}\text { Symptomatic. }>50 \% \text { in bed. Capable of only limited self-care, } \\
\text { confined to bed or chair } 50 \% \text { or more of waking hours }\end{array}$ \\
\hline 9 & & 4 & Bedbound \\
\hline 10 & Worst & 5 & Death \\
\hline
\end{tabular}




\section{Evaluation of Toxicity}

Safety was assessed on the basis of adverse events, both hematologic, in the clinical laboratory, and gastrointestinal, in physical examination findings. All adverse events that occurred after randomization, within 3 mo after the last injection of 223Ra, were reported and evaluated for their potential relationship to the study drug. Only patients with WHO's grade of 3-4 from the initial cycle of 223Ra to $3 \mathrm{mo}$ after the last administered dose were classified as having hematologic toxicity (ht) (Table-2).

\section{Statistical analysis}

Patient and clinical characteristics were summarized using descriptive statistics.

Median and range or 95\% confidence interval for quantitative variables and categorical variables are shown as number (\%). Kaplan-Meier estimates were produced for the cumulative incidence of OS, according to number of cycles of 223Ra, ECOG, basal level of Hb, metastatic involvement in bone bone-scintigraphy, and start of 223Ra-therapy. All statistical analyses were performed using SPSS for Windows.

\section{RESULTS}

Patients had a median age of 72years (range $=39-88$ ) and received a total of 183 cycles of 223Ra with a median follow-up time of $11 \mathrm{mo}$ (range $=1.3-41$ ).

25/40p (63\%) received the 6 cycles of 223Ra, $1 \mathrm{p}(2 \%)$ received 5 cycles, and $14 \mathrm{p} \mathrm{(35 \% )}$ received 4 cycles or less. Out of the $14 \mathrm{p}$ who received 4 cycles or less, $1 \mathrm{p}$ discontinued the treatment due to unalleviated pain, $1 \mathrm{p}$ due to progres- sion, $2 p$ died, $3 p$ for comorbidities, $4 p$ continued the treatment at another hospital and $3 p$ suspended treatment due administrative problems. In Table-3, the baseline demographic and clinical characteristics of the $40 \mathrm{p}$ are described. Of the $26 p$ who finished the treatment, 21p (81\%) had a reduction in skeletal pain, the ECOG improved in $9 p(35 \%)$, and $14 p(54 \%)$ had a reduction in analgesic requirements (Figure-1).

Median value of baseline ALP in our cohort was $210.5 \mathrm{U} / \mathrm{L}-$ (range $=53-2370.8$ ). We found a decrease in serum ALP level in 23/26p (88.5\%), $17 p$ with a reduction of $>25 \%$ and $6 p<25 \%$, while $3 p$ had an increase $(2 p>25 \%$ and $1 p<25 \%$ ) (Figure-2). The average reduction was $42.2 \%$ - (SD 28.1). Changes in ALP may be a useful marker for monitoring treatment with 223Ra. Further, the ALP baseline level was associated with decrease of OS.

PSA was recorded prior to the first and final cycle and the median PSA showed an upward trend of $93.55 \mathrm{ng} / \mathrm{mL}$ at the beginning and $142.16 \mathrm{ng} / \mathrm{mL}$ at the end.

Median OS was $17.1 \mathrm{mo}$ - $($ range $=1.2-41.1$, CI 95\% 6.5-27.7) (Figure-3A), Median follow-up was 11.2mo- (range=1.3-45.2). 26/40p received complete treatments of 223Ra without reaching a median $0 S$, and $14 p$ received incomplete treatments with a median OS of 13.6mo-(CI 95\% 1.625.6) (Figure-3B). PFS was 9.8mo- (CI95\%6.6-13). $26 \mathrm{p}$ with complete treatments were $11.1 \mathrm{mo}$ (CI $95 \%$ 8.5-13.8), while those $14 \mathrm{p}$ with incomplete treatments were 5mo- (CI95\% 2.8-7.3). TTP was 7.1mo- (CI 95\% 3.9-10.3).

The univariate analysis showed that the baseline clinical variables, such as ECOG, $\mathrm{Hb}$, bone-scintigraphy, ALP, and PSA, were independently associated with OS (Figures 3 C-E). Patients

Table 2 - Hematologic toxicity (according to WHO criteria).

\begin{tabular}{cccc}
\hline & $\mathrm{Hb}(\mathrm{g} / \mathrm{dL})$ & ANC $(/ \mathrm{mm} 3)$ & Platelets $\left(/ \mathrm{mm}^{3}\right)$ \\
\hline 1 & $>10.0$ & $>1,500$ & $>75,000$ \\
2 & 8.0 to<10.0 & 1,000 to $<1,500$ & 50,000 to $<75,000$ \\
3 & $<8.0$ (transfusion indicated) & 500 to $<1,000$ & 25,000 to $<50,000$ \\
4 & Life-threatening; urgent intervention indicated & $<500$ & $<25,000$ \\
\hline
\end{tabular}


Table 3 - Baseline patients' characteristics.

\begin{tabular}{|c|c|c|c|}
\hline Baseline variable & & $\mathrm{n}(\%)$ Nalue & Range \\
\hline Age & Mean & 71 & $39-88$ years \\
\hline \multirow[t]{4}{*}{ ECOG status } & Mean & 1.92 & $1-4$ \\
\hline & 1 & $8(20 \%)$ & \\
\hline & 2 & $23(58 \%)$ & \\
\hline & 3 & $9(22 \%)$ & \\
\hline \multirow[t]{3}{*}{ CPL } & 1 & $11(27 \%)$ & \\
\hline & 2 & $6(15 \%)$ & \\
\hline & 3 & $23(58 \%)$ & \\
\hline \multirow[t]{4}{*}{ VAS } & Mild (1-3) & $13(32.5 \%)$ & \\
\hline & Moderade (4-6) & $10(25 \%)$ & \\
\hline & Severe (7-9) & $13(32.5 \%)$ & \\
\hline & Maximum (10) & $4(10 \%)$ & \\
\hline \multirow[t]{3}{*}{ Bone metastases (Bone-Scan) } & $2-6$ & $13(32 \%)$ & \\
\hline & $>6$ & $21(53 \%)$ & \\
\hline & Superscan & $6(15 \%)$ & \\
\hline \multirow[t]{3}{*}{$\mathrm{Hb}$} & Median & 12.8 & $9.2-16.9$ \\
\hline & $<13$ & $23(57.5 \%)$ & \\
\hline & $>13$ & $17(42.5 \%)$ & \\
\hline \multirow[t]{4}{*}{ PSA } & Median & 93.5 & $0.26-24784$ \\
\hline & $0-20$ & $8(20 \%)$ & \\
\hline & 21-99 & $15(37 \%)$ & \\
\hline & $>100$ & $17(43 \%)$ & \\
\hline \multirow[t]{3}{*}{ ALP } & Median & 220 & $53-2370$ \\
\hline & $\geq 200$ & $19(47 \%)$ & \\
\hline & $<200$ & $21(53 \%)$ & \\
\hline \multirow[t]{4}{*}{ Previous systemic treatments } & Abiraterone & $16(40 \%)$ & \\
\hline & Enzalutamide & $3(7 \%)$ & \\
\hline & Chemotherapy & $8(20 \%)$ & \\
\hline & Previous Bone Radiotherapy & $19(47 \%)$ & \\
\hline
\end{tabular}


Figure 1 - Trend in VAS from the $1^{\text {st }}$ to the $6^{\text {th223 }}$ Ra cycles. There is a decrease in pain during complete therapy. The main pain improvement is visualized during the first three cycles of treatment.

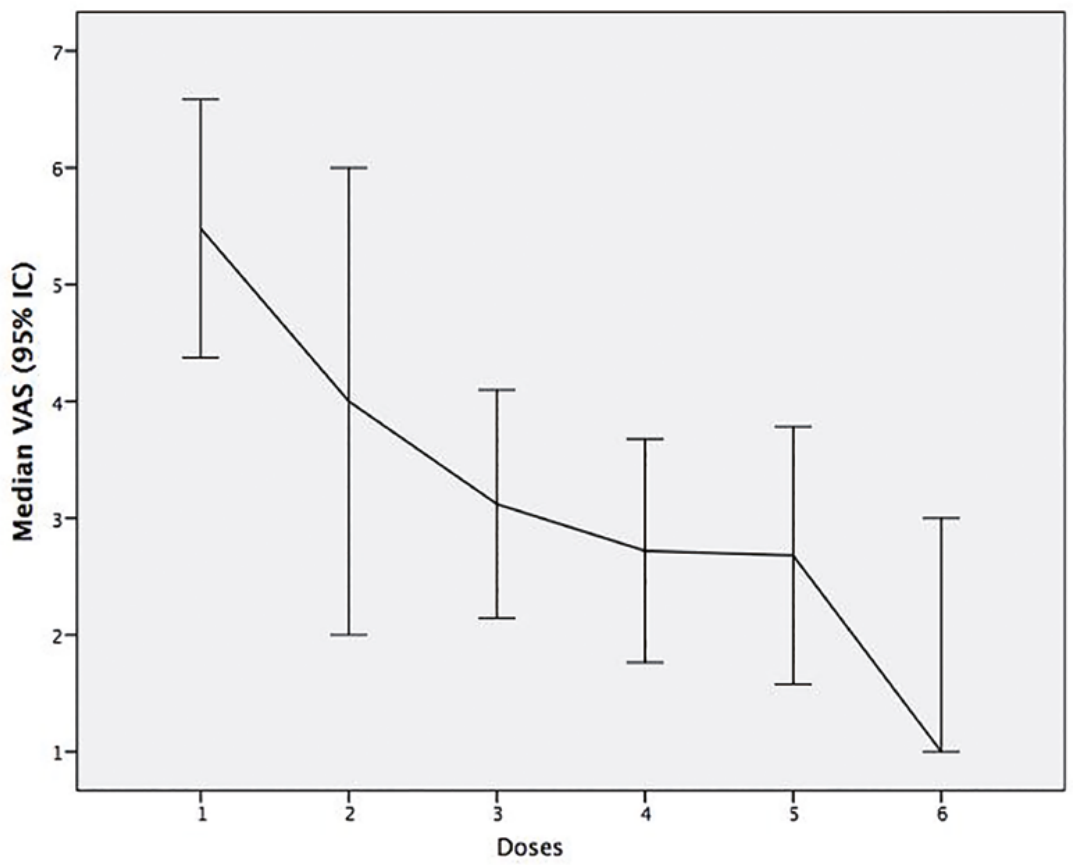

Figure 2 - Comparison ALP measurements before and after therapy with ${ }^{223} \mathrm{Ra}$.

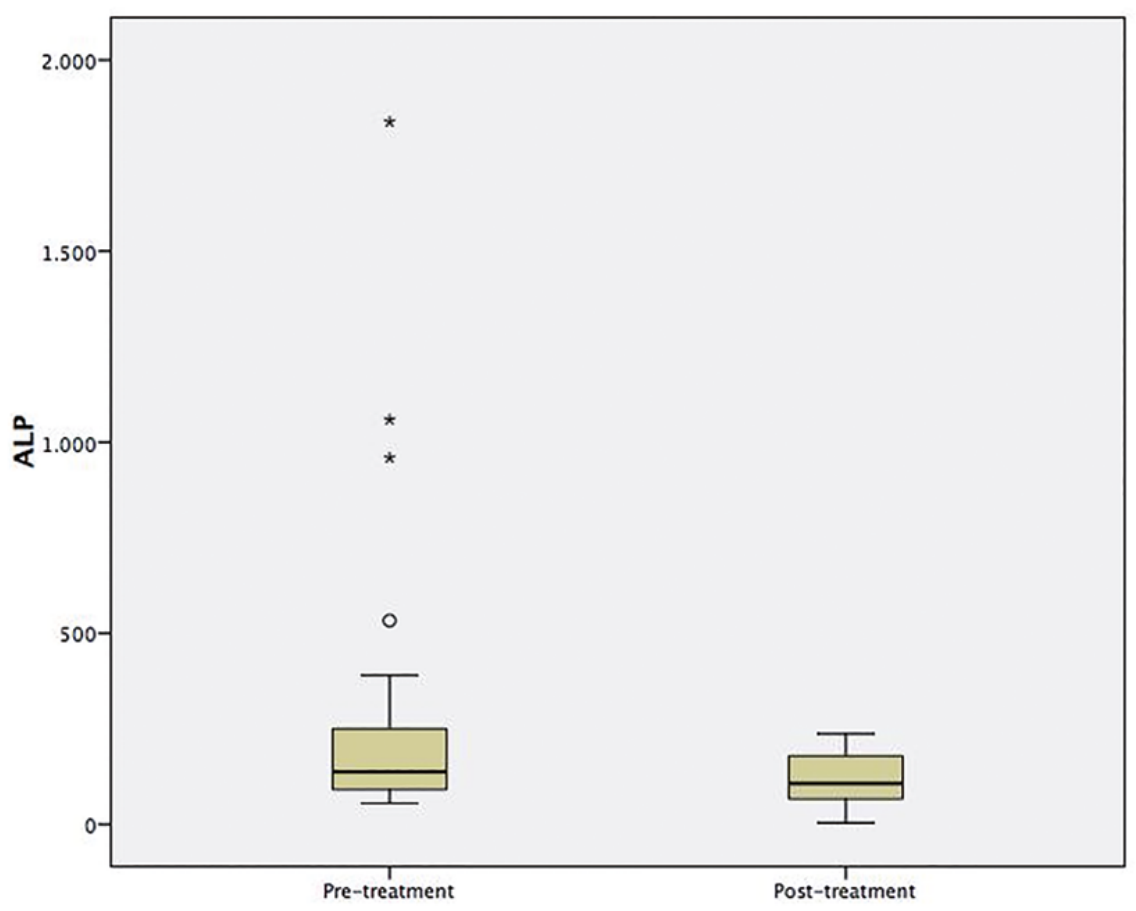


Figure 3 - Kaplan-Meier estimate showing the overall survival in our cohort according to different variables. A. Overall survival. B. Number of doses of ${ }^{223}$ Ra. C. ECOG performance status. D. Basal level Hb. E. Metastatic involvement in bone scan. F. Start of ${ }^{223}$ Ra therapy.
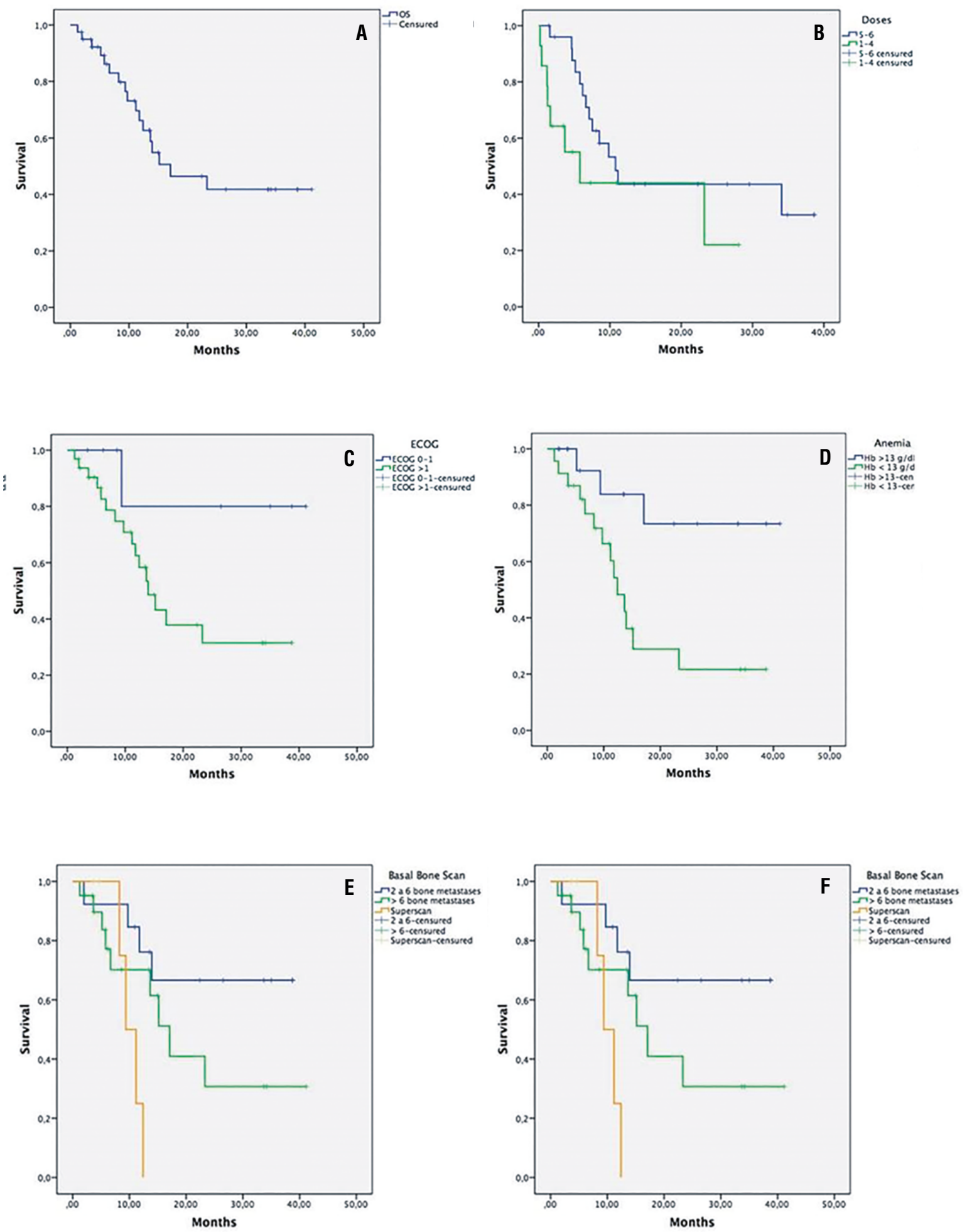
with ECOG $>1$, baseline $\mathrm{Hb}$ levels $<13 \mathrm{~g} / \mathrm{dL}$, superscan on bone-scintigraphy, baseline ALP levels $>200 \mathrm{U} / \mathrm{L}$, and baseline PSA levels $>100 \mathrm{ng} / \mathrm{mL}$ were associated with an increased risk of death. $11 / 40 \mathrm{p}$ started therapy with $223 \mathrm{Ra}$ as the first line without reaching a median OS, while19 had been heavily pre-treated, receiving $223 \mathrm{Ra}$ later, with a median OS of $12.4 \mathrm{mo}$, and 13 received treatment concomitant with other therapies (10p: abiratero- ne and 3p: enzalutamide; 6/13p: bisphosphonates) with a median OS of 13.6mo (Figure-3F). 8/40p $(20 \%)$ were treated with biphosphonates before starting 223Ra, and 15/40p (37\%) received concomitant treatment. Results of univariable analysis of OS are shown in Table-4.

Hematologic and gastrointestinal adverse events occurred in 57\% and 42\% respectively (Table-5). Ht occurred in 7/40p (18\%). In $5 p$ it

Table 4 - Univariate analysis of OS in relation to baseline variables.

\begin{tabular}{|c|c|c|c|c|c|}
\hline \multirow[t]{2}{*}{ Variable } & & & \multirow{2}{*}{$\begin{array}{c}\text { Patients }(\mathrm{n}=40) \\
\mathrm{n}(\%)\end{array}$} & \multicolumn{2}{|c|}{ OS } \\
\hline & & & & Median & Cl95\% \\
\hline \multirow[t]{2}{*}{ ECOG } & \multicolumn{2}{|c|}{$0-1$} & $8(20)$ & Not reached & \\
\hline & \multicolumn{2}{|c|}{$>1$} & $32(80)$ & 14 & $10.2-17.6$ \\
\hline \multirow[t]{2}{*}{$\mathrm{Hb}$} & \multicolumn{2}{|c|}{$>13 \mathrm{~g} / \mathrm{dL}$} & $17(42)$ & Not reached & \\
\hline & \multicolumn{2}{|c|}{$<12.9 \mathrm{~g} / \mathrm{dL}$} & $23(58)$ & 12.4 & $9.2-15.5$ \\
\hline \multirow[t]{3}{*}{ PSA } & \multicolumn{2}{|c|}{$0-20 \mathrm{ng} / \mathrm{mL}$} & $8(20)$ & Not reached & \\
\hline & \multicolumn{2}{|c|}{$21-99 \mathrm{ng} / \mathrm{mL}$} & $14(35)$ & 15.2 & 10.6-19.7 \\
\hline & \multicolumn{2}{|c|}{$>100 \mathrm{ng} / \mathrm{mL}$} & $18(45)$ & 12.4 & $7.6-17.2$ \\
\hline \multirow[t]{3}{*}{ ALP } & \multicolumn{2}{|c|}{ Missing data } & $1(2)$ & & \\
\hline & \multicolumn{2}{|c|}{$<200 \mathrm{U} / \mathrm{L}$} & $19(48)$ & Not reached & \\
\hline & \multicolumn{2}{|c|}{$>200 \mathrm{U} / \mathrm{L}$} & $20(50)$ & 12.4 & $7.5-17.3$ \\
\hline \multirow[t]{3}{*}{ Bone-Scan } & \multicolumn{2}{|c|}{2 a 6} & $13(32)$ & Not reached & \\
\hline & \multicolumn{2}{|c|}{$>6$} & $21(53)$ & 17.1 & $12.3-21.9$ \\
\hline & \multicolumn{2}{|c|}{ Superscan } & $6(15)$ & 9.4 & $6.5-12.2$ \\
\hline \multirow[t]{8}{*}{${ }^{223}$ Ra Therapy } & \multicolumn{2}{|c|}{ First line } & $11(27)$ & Not reached & \\
\hline & \multirow{6}{*}{$\begin{array}{l}\text { Heavily pre-treated } \\
\text { before }\end{array}$} & Total & $19(47)$ & 12.4 & $8.1-16.7$ \\
\hline & & Abiraterone & $10(25)$ & 9.7 & $6-13.5$ \\
\hline & & Enzalutamide & $1(2)$ & & \\
\hline & & Chemotherapy & $2(5)$ & & \\
\hline & & $\begin{array}{c}\text { Chemotherapy + } \\
\text { abiraterone }\end{array}$ & $4(10)$ & 15.2 & $0.1-32.4$ \\
\hline & & $\begin{array}{c}\text { Chemotherapy + } \\
\text { enzalutamide + } \\
\text { abiraterone }\end{array}$ & $2(5)$ & & \\
\hline & \multicolumn{2}{|c|}{ Treatment concomitant } & $13(32)$ & 13.6 & 7.8-19.5 \\
\hline
\end{tabular}


Table 5 - Adverse events graded according to the Common Terminology Criteria for Adverse Events, version 4.0.

\begin{tabular}{|c|c|c|c|c|c|c|c|c|c|c|c|c|c|}
\hline \multirow[t]{3}{*}{$p$} & \multirow[t]{3}{*}{ Doses } & \multicolumn{6}{|c|}{ Hematologic adverse event (Grades) } & \multicolumn{6}{|c|}{ Gastrointestinal adverse event (Grades) } \\
\hline & & \multicolumn{2}{|c|}{ Anemia } & \multicolumn{2}{|c|}{ Neutropenia } & \multicolumn{2}{|c|}{ Thrombocytopenia } & \multicolumn{2}{|c|}{ Nausea } & \multicolumn{2}{|c|}{ Vomit } & \multicolumn{2}{|c|}{ Diarrhea } \\
\hline & & $1-2$ & $3-4$ & $1-2$ & $3-4$ & $1-2$ & 3-4 & $1-2$ & $3-4$ & $1-2$ & $3-4$ & $1-2$ & $3-4$ \\
\hline 1 & 4 & & & & & & & & & & & & \\
\hline 2 & 2 & $x$ & & $x$ & & & & & & & & & \\
\hline 3 & 2 & $x$ & & $x$ & & $x$ & & $\mathrm{x}$ & & $\mathrm{x}$ & & & \\
\hline 4 & 6 & $x$ & & & & & & & & & & & \\
\hline 5 & 6 & & & $x$ & & & & $\mathrm{x}$ & & & & $x$ & \\
\hline 6 & 6 & $x$ & & & $x$ & $x$ & & & & & & & \\
\hline 7 & 6 & & & $x$ & & & & & & & & & \\
\hline 8 & 6 & $x$ & & & & & & & & & & & \\
\hline 9 & 6 & & & $x$ & & & & & & & & & \\
\hline 10 & 6 & $X$ & & $x$ & & & & $X$ & & $X$ & & $x$ & \\
\hline 11 & 6 & & $x$ & & & & & & $x$ & & $x$ & & \\
\hline 12 & 3 & & & & & & & & & & & & \\
\hline 13 & 6 & & & $x$ & & & & $X$ & & $x$ & & $x$ & \\
\hline 14 & 6 & & & $x$ & & & & $x$ & & & & $X$ & \\
\hline 15 & 6 & & & $x$ & & & & & & & & & \\
\hline 16 & 6 & $x$ & & & & & & $X$ & & $X$ & & & \\
\hline 17 & 6 & & $X$ & & $x$ & & & $X$ & & $X$ & & & \\
\hline 18 & 2 & $X$ & & & & & & $X$ & & & & & \\
\hline 19 & 6 & & & $x$ & & & & $X$ & & & & & \\
\hline 20 & 6 & & & & & & & & & & & & \\
\hline 21 & 6 & $x$ & & $X$ & & & & & & & & & \\
\hline 22 & 2 & $x$ & & & & & & $X$ & & $X$ & & & \\
\hline 23 & 6 & $x$ & & $x$ & & $X$ & & & & & & & \\
\hline 24 & 3 & $x$ & & & & & & & & & & & \\
\hline 25 & 6 & & & & & & & & & & & & \\
\hline 26 & 6 & $x$ & & & & & & $X$ & & & & & \\
\hline 27 & 6 & & $X$ & $X$ & & $X$ & & & & & & & \\
\hline 28 & 2 & & & & & & & & & & & & \\
\hline 29 & 2 & & & $X$ & & & & & & & & & \\
\hline 30 & 4 & & $X$ & $x$ & & $X$ & & $X$ & & & & $x$ & \\
\hline 31 & 6 & $x$ & & & & & & $x$ & & & & & \\
\hline 32 & 6 & & & & & $X$ & & $x$ & & & & & \\
\hline 33 & 1 & $X$ & & $x$ & & & & & & & & & \\
\hline 34 & 6 & $x$ & & $x$ & & $X$ & & $X$ & & & & & \\
\hline 35 & 5 & & & $x$ & & & & & & & & & \\
\hline 36 & 6 & & & & & & & & & & & & \\
\hline 37 & 4 & $x$ & & & & & & & & & & $x$ & \\
\hline 38 & 3 & & $X$ & $x$ & & $X$ & & $X$ & & $X$ & & & \\
\hline 39 & 6 & $X$ & & $X$ & & $X$ & & & & & & $X$ & \\
\hline 40 & 1 & & & & & & & & & & & & \\
\hline
\end{tabular}


was grade 3 ( $4 \mathrm{p}=$ anemia and $1 \mathrm{p}=$ neutropenia) and in $2 p$ it was grade $4(1 \mathrm{p}=$ anemia and neutropenia and $1 p=$ anemia). Of the $7 p$ who developed $\mathrm{Ht}$, 3 received treatments before their 223Ra cycles $(1 \mathrm{p}=$ chemotherapy and EBRT, $1 \mathrm{p}=$ abiraterone and EBRT and $1 p=E B R T$ ) and $2 p$ received concurrent abiraterone during 223Ra treatment. 19/40p developed gastrointestinal symptoms, nausea being the most significant in $17 \mathrm{p}(89 \%)$.

\section{DISCUSSION}

Over the last years, the treatment for mCRPC has evolved considerably due to the introduction of new therapeutic agents (cabazitaxel/enzalutamide/abiraterone/223Ra). However, the main challenge, finding the best therapeutic sequencing, remains, and it could have a significant impact in terms of clinical improvement and survival. When managing mCRPC patients, many of the bone-related parameters frequently used to determine outcome denote dismal prospects for survival, and so determining which patients will benefit from therapy, in terms of OS, PFS, bone marrow depletion, and SREs, is more difficult (13, 14). As a result, there is a need to identify factors that will predict outcome, especially for new therapies, like 223Ra. The aim of this study was to evaluate in a clinical reality the role of baseline clinical variables (ECOG/ALP/Hb/number of bone metastases, and previous treatments) associated with the OS and toxicity of 223Ra-therapy, whose purpose is to identify factors that may predict a better response to treatment and provide information on the most appropriate time for the application of 223Ra. A interdisciplinary approach facilitates identification of patients who are suitable for 223Ra treatment. It has been established that the effectiveness of the treatment on survival is obtained after at least five administrations of 223Ra (15). For this reason, in this study, complete treatment for patients was defined as 5-6 cycles.

The results of this study are consistent with the findings reported in the ALSYMPCA (7), confirming that treatment with 223Ra leads to an improvement in pain rate and QoL, which was evaluated with EQ-5D-5L-score and will be reviewed later in a specific publication. Different analyses demonstrated that this treatment is well-tolerated, with a modest objective response rate, and effective in reducing ALP levels, with a clinical benefit and a positive effect on OS (16-18). Our results showed that the response to 223Ra was first clinical and later biochemical, with a moderate decrease in ALP. Taking into consideration some experiences in the literature, we evaluated the variations of ALP to assess the effect of 223Ra treatment (19-21). We observed a significant impact of 223Ra, reducing serum ALP levels by $88.5 \%$, and we noted that the majority of these variations were associated with better pain control, decreased opioid consumption, and better functional status.

In mCRPC patients treated with 223Ra, several baseline prognostic markers associated with OS have been proposed, such as ECOG, ALP and $\mathrm{Hb}$ values, and prior systemic treatments. In Table- 6 , we describe the baseline clinical characteristics of the patients who received Ra 223 in the three different lines of therapy. Nonetheless, currently, no predictive clinical variable assessing the therapeutic benefit of 223Ra has been identified (13). The univariate analysis showed that factors like ECOG, VAS, Hb and ALP values were independently associated with OS. Decreased survival rates were seen in patients with basal $\mathrm{Hb}<13 \mathrm{~g} / \mathrm{dL}$, superscan on bone-scintigraphy, PSA $>100 \mathrm{ng} / \mathrm{mL}$, ALP $>200 U / 1$, ECOG $>1$, and those who did not finish the treatment. The use of 223Ra as the first line of therapy showed a greater OS, which suggests that early treatment is beneficial. However, due to the limited number in our sample, we were unable to draw definitive conclusions.

Elba Etchebehere et al. reported a significant benefit in the use of abiraterone concomitant to 223Ra in terms of OS, PFS, and BeFs (univariable: $p<0.002$ and multivariable: $p<0.044$ ). The use of abiraterone with 223Ra reduced the risk of death and SREs by $77 \%$ and the risk of progression by $68 \%$ (22). However, a recent analysis from the ERA223 trial (23) showed that the simultaneous initiation of the three agents (abiraterone+prednisone/ prednisolone with 223Ra) led to an increased risk of fractures and deaths. In our study, in patients who received a concomitance of 223Ra plus abiraterone (10p), OS was lowest, with a median of 
Table 6 - Patients' baseline characteristics of treated with 223Ra in the 3 lines of therapy.

\begin{tabular}{|c|c|c|c|c|}
\hline${ }^{223}$ Ra therapy & & First line (11p) & $\begin{array}{l}\text { Concomitant (Abiraterone/Enzalutamide) } \\
\qquad(13 p)\end{array}$ & $\begin{array}{l}\text { Followed by other } \\
\text { treatments }(19 p)\end{array}$ \\
\hline Baseline variable & & $n$ & $n$ & $n$ \\
\hline Age & Mean & 70 years & 71 years & 71 years \\
\hline \multirow[t]{2}{*}{ ECOG status } & 1 & 3 & 2 & 3 \\
\hline & $\geq 2$ & 8 & 11 & 16 \\
\hline \multirow[t]{2}{*}{ CPL } & $1-2$ & 8 & 2 & 8 \\
\hline & 3 & 3 & 11 & 11 \\
\hline \multirow{3}{*}{$\begin{array}{l}\text { Bone metastases } \\
\text { (Bone-Scan) }\end{array}$} & $2-6$ & 6 & 4 & 5 \\
\hline & $>6$ & 5 & 7 & 10 \\
\hline & Superscan & 0 & 2 & 4 \\
\hline \multirow[t]{2}{*}{$\mathrm{Hb}(\mathrm{g} / \mathrm{dL})$} & $<12.9$ & 4 & 10 & 11 \\
\hline & $>13$ & 7 & 3 & 8 \\
\hline \multirow[t]{2}{*}{ PSA (ng/mL) } & $<99.9$ & 10 & 7 & 7 \\
\hline & $>100$ & 1 & 6 & 12 \\
\hline \multirow[t]{2}{*}{$\operatorname{ALP}(\mathrm{U} / \mathrm{L})$} & $<199.9$ & 6 & 5 & 12 \\
\hline & $>200$ & 5 & 8 & \\
\hline
\end{tabular}

13.6mo, without significant changes in the presence of SREs. $16 / 19 p$ heavily pre-treated had received abiraterone and within this group, the majority had the most unfavorable baseline characteristics, such as $\mathrm{Hb}<13 \mathrm{~g} / \mathrm{dL}$, PSA $>100 \mathrm{ng} / \mathrm{mL}$, ECOG $>2, \mathrm{CPL}=3$, and greater bone compromise, resulting in lower OS (Table-4). Anemia was the most frequent side effect associated with 223Ra $(24,25)$. In the present study, treatment with 223Ra was well-tolerated with only 7.5\% of patients experiencing severe anemia (grade 4). The toxicity was manageable and reversible in most cases. The limitations of this study can be attributed to a limited number of patients, heterogeneity of the population and patient's socio-economic history, considering that some had delays in the administration of the cycles or were changed from hospital. In fact, longer time frames and larger sample sizes are needed to acquire more conclusive results in terms of OS and tolerance to other therapies after treatment with 223Ra. Nevertheless, our study provides valuable information from routine clinical practice in identifying patients who would benefit the most from 223Ra therapy, as well as the most appropriate time to initiate such treatment.

\section{CONCLUSIONS}

223Ra therapy demonstrates maximum efficacy in $\mathrm{mCRPC}$ patients who receive the full treatment. It is necessary to select suitable patients who will benefit from this therapy. Basal low $\mathrm{Hb}$ levels, bone marrow involvement and an altered performance status were the main factors that decreased survival in our patients. The use of 223Ra as the first line of therapy showed a higher OS, therefore, it should be considered relatively early in the course of treatment. Toxicity was manageable and reversible in most cases.

\section{ABBREVIATIONS}

223Ra $=$ Radium -223

ANC $=$ Absolute neutrophil count

ALP $=$ Alkaline phosphatase 
ALSYMPCA = ALpharadin in SYMptomatic Prostate CAncer

$\mathrm{BMF}=$ Bone marrow failure

$\mathrm{CPL}=$ WHO's Cancer Pain Ladder

ECOG $=$ Eastern Cooperative Oncology Group

EBRT $=$ External beam radiation-therapy

FDA $=$ Food and Drug Administration

$\mathrm{Hb}=$ Hemoglobin

$\mathrm{Ht}=$ hematological toxicity

LDH $=$ Lactate dehydrogenase

mCRCP $=$ Metastatic castration resistant prostate cancer

OS $=$ Overall survival

$\mathrm{p}=$ Patients

$\mathrm{PC}=$ Platelet count

PFS = Progression-free survival

PSA $=$ Prostate specific antigen

SREs $=$ The skeletal related events

TTP = Time to progression

VAS = Visual Analogue Scale for pain

\section{CONFLICT OF INTEREST}

None declared.

\section{REFERENCES}

1. Bubendorf L, Schöpfer A, Wagner U, Sauter G, Moch H, Willi N, et al. Metastatic patterns of prostate cancer: an autopsy study of 1,589 patients. Hum Pathol. 2000;31:578-83.

2. Yong $\mathrm{C}$, Onukwugha $\mathrm{E}$, Mullins CD. Clinical and economic burden of bone metastasis and skeletal-related events in prostate cancer. Curr Opin Oncol. 2014;26:274-83.

3. Iranikhah M, Stricker S, Freeman MK. Future of bisphosphonates and denosumab for men with advanced prostate cancer. Cancer Manag Res. 2014;6:217-24.

4. Ezzell EE, Chang KS, George BJ. New agents in the arsenal to fight castrate-resistant prostate cancer. Curr Oncol Rep. 2013;15:239-48.

5. FDA Approves New Drug for Advanced Prostate Cancer. US Food and Drug Administration. Available at. <www.fda.gov/ NewsEvents/Newsroom/PressAnnouncements/ucm 352363. htm> Accessed May 15, 2013.

6. Kluetz PG, Pierce W, Maher VE, Zhang H, Tang S, Song P, et al. Radium Ra 223 dichloride injection: U.S. Food and Drug Administration drug approval summary. Clin Cancer Res. 2014;20:9-14.
7. Parker C, Nilsson S, Heinrich D, Helle SI, O'Sullivan JM, Fosså $\mathrm{SD}$, et al. Alpha emitter radium-223 and survival in metastatic prostate cancer. N Engl J Med. 2013;369:213-23.

8. Cheetham PJ, Petrylak DP. Alpha particles as radiopharmaceuticals in the treatment of bone metastases: mechanism of action of radium-223 chloride (Alpharadin) and radiation protection. Oncology (Williston Park). 2012;26:330-41.

9. Jadvar H, Challa S, Quinn DI, Conti PS. One-Year Postapproval Clinical Experience with Radium-223 Dichloride in Patients with Metastatic Castrate-Resistant Prostate Cancer. Cancer Biother Radiopharm. 2015;30:195-9.

10. Poeppel TD, Handkiewicz-Junak D, Andreeff M, Becherer A, Bockisch A, Fricke $E$, et al. EANM guideline for radionuclide therapy with radium-223 of metastatic castration-resistant prostate cancer. Eur J Nucl Med Mol Imaging. 2018;45:824-45.

11. Nilsson S, Franzén L, Parker C, Tyrrell C, Blom R, Tennvall J, et al. Two-year survival follow-up of the randomized, doubleblind, placebo-controlled phase II study of radium-223 chloride in patients with castration-resistant prostate cancer and bone metastases. Clin Genitourin Cancer. 2013;11:20-6.

12. Jadvar H, Quinn DI. Targeted -particle therapy of bone metastases in prostate cancer. Clin Nucl Med. 2013;38:966-71.

13. Du Y, Carrio I, De Vincentis G, Fanti S, Ilhan H, Mommsen C, et al. Practical recommendations for radium-223 treatment of metastatic castration-resistant prostate cancer. Eur J Nucl Med Mol Imaging. 2017;44:1671-8.

14. Frantellizzi V, Farcomeni A, Follacchio GA, Pacilio M, Pellegrini $R$, Pani R, et al. A 3-variable prognostic score (3-PS) for overall survival prediction in metastatic castration-resistant prostate cancer treated with (223)Radium-dichloride. Ann Nucl Med. 2018;32:142-8.

15. O. Sartor, R.E. Coleman, M.J. Morris, S. Nilsson, N. Shore, C. Sweeney, et al. 2530 Baseline characteristics, number of radium-223 (Ra-223) injections, and overall survival (OS) in US Expanded Access Program (EAP) and ALSYMPCA. 2015, 51 (Suppl. 3): S484-5.

16. Sartor 0 , Coleman R, Nilsson S, Heinrich D, Helle SI, O'Sullivan $\mathrm{JM}$, et al. Effect of radium-223 dichloride on symptomatic skeletal events in patients with castration-resistant prostate cancer and bone metastases: results from a phase 3, doubleblind, randomised trial. Lancet Oncol. 2014;15:738-46.

17. Hoskin P, Sartor O, O'Sullivan JM, Johannessen DC, Helle SI, Logue J, et al. Efficacy and safety of radium-223 dichloride in patients with castration-resistant prostate cancer and symptomatic bone metastases, with or without previous docetaxel use: a prespecified subgroup analysis from the randomised, double-blind, phase 3 ALSYMPCA trial. Lancet Oncol. 2014;15:1397-406. 
18. Yin L, Hu Q, Hartmann RW. Recent progress in pharmaceutical therapies for castration-resistant prostate cancer. Int J Mol Sci. 2013;14:13958-78.

19. Gartrell BA, Coleman R, Efstathiou E, Fizazi K, Logothetis CJ, Smith MR, et al. Metastatic Prostate Cancer and the Bone: Significance and Therapeutic Options. Eur Urol. 2015;68:850-8.

20. Sonpavde G, Pond GR, Berry WR, de Wit R, Armstrong AJ, Eisenberger MA, et al. Serum alkaline phosphatase changes predict survival independent of PSA changes in men with castration-resistant prostate cancer and bone metastasis eceiving chemotherapy. Urol Oncol. 2012;30:607-13.

21. Hague C, Logue JP. Clinical experience with radium-223 in the treatment of patients with advanced castrateresistant prostate cancer and symptomatic bone metastases. Ther Adv Urol. 2016;8:175-80.

22. Etchebehere EC, Milton DR, Araujo JC, Swanston NM, Macapinlac HA, Rohren EM. Factors affecting (223)Ra therapy: clinical experience after 532 cycles from a single institution. Eur J Nucl Med Mol Imaging. 2016;43:8-20.
23. Smith M, Parker C, Saad F, Miller K, Tombal B, Ng QS, et al. Addition of radium-223 to abiraterone acetate and prednisone or prednisolone in patients with castration-resistant prostate cancer and bone metastases (ERA 223): a randomised, double-blind, placebo-controlled, phase 3 trial. Lancet Oncol. 2019;20:408-19. Erratum in: Lancet Oncol. 2019;20:e559.

24. Nilsson S. Alpha-emitter radium-223 in the management of solid tumors: current status and future directions. Am Soc Clin Oncol Educ Book. 2014:e132-9.

25. Wilson JM, Dearnaley DP, Syndikus I, Khoo V, Birtle A, Bloomfield D, et al. The Efficacy and Safety of Conventional and Hypofractionated High-Dose Radiation Therapy for Prostate Cancer in an Elderly Population: A Subgroup Analysis of the CHHiP Trial. Int J Radiat Oncol Biol Phys. 2018;100:1179-89.

Correspondence address: Monica Vidal, MD Hospital Pablo Tobon Uribe - Radiología Calle, 78B\# 69-240, Medellin, Antioquia 005001, Colombia Telehpone.: + 574 445-9000 E-mail: mvidal@hptu.org.co 